\title{
Adult Non-T Non-B Acute Lymphoblastic Leukemia
}

National Cancer Institute

\section{Source}

National Cancer Institute. Adult Non-T Non-B Acute Lymphoblastic Leukemia. NCI

Thesaurus. Code C114574.

Non-T non-B acute lymphoblastic leukemia that occurs during adulthood. 